\title{
Fabrication of PVA polymer films with improved antibacterial activity by fine-tuning via organic acids for food packaging applications
}

\author{
Sanjeevamuthu Suganthi ${ }^{1}$ Shanmugam Vignesh ${ }^{2} \cdot$ Jeyaperumal Kalyana Sundar $^{2} \cdot$ Vairamuthu Raj $^{1}$
}

Received: 25 December 2019 / Accepted: 18 February 2020 / Published online: 30 March 2020

(c) The Author(s) 2020

\begin{abstract}
In this study, organic acids were used as cross-linker with polyvinyl alcohol (PVA) films prepared by a solution-casting method for food packing applications. The effect of incorporating three different organic acids, i.e., malic acid (MA), tartaric acid (TA), and lactic acid (LA), on the physicochemical and biological properties of PVA was explored in detail. The crystalline phase, optical absorption, and functional groups were examined via UV-Vis and Fourier transform infrared spectroscopy. Thermal, microstructural, and surface investigations were conducted by thermogravimetric analysis and scanning electron microscopy, and the antibacterial activity was evaluated. The surface topography and roughness were found to have a strong effect on the bactericidal properties of the films, as confirmed by atomic force microscopy. Among the considered films, PVA/LA exhibited the highest bacterial inhibition, which was largely due to its capacity to modify the local $\mathrm{pH}$ and alter the permeability of the microbial layer by disrupting bacteria-substrate interaction. In general, the composite film was found to have attractive properties and can be considered as a food packaging material with low environmental impact based on polyvinyl alcohol.
\end{abstract}

Keywords Polyvinyl alcohol · Organic acids · Antibacterial activity $\cdot$ Food packaging $\cdot$ Physicochemical properties

\section{Introduction}

Biodegradable food packaging systems are in increasing demand in response to the environmental issues of modern society. The long-term environmental impact of plastic packaging waste is an increasing global concern with regard to the safety of marine environments, since limited disposal methods pose a serious challenge in food safety (Shankar and Rhim 2018; Han et al. 2018; Okunola et al. 2019). Such issues have sparked increasing interest in the development of biodegradable packaging materials using polymers with properties that are comparable to those of synthetic plastic packaging materials. In particular, recent efforts have been focused on the development of antimicrobial and

Vairamuthu Raj

doctorvraaj@gmail.com

1 Advanced Materials Research Laboratory, Department of Chemistry, Periyar University, Salem, Tamil Nadu 636 011, India

2 Materials Science Research Laboratory, Department of Physics, Periyar University, Salem, Tamil Nadu 636 011, India biodegradable polymer films for food packaging applications with good mechanical stability, while preserving the freshness and flavor of food products with longer shelf life to reduce food waste from spoilage (Ahmed et al. 2017; Agrillo et al. 2019; Huang et al. 2019). Traditional petroleum-based polymeric materials, including polyethylene (Manikantan et al. 2014), polycarbonate (Dhapte et al. 2015), polyethylene terephthalate (Lei et al. 2014), polyvinylchloride, polypropylene, polystyrene, and polyamides have typically been used as packaging materials. However, environmental concerns with respect to their production and disposal have necessitated the search for environmentally benign alternatives with comparable thermal, mechanical, and barrier properties. Polymer films offer an attractive alternative because of their naturally good thermal, mechanical, and inhibitory properties, easy accessibility, facile production, and biodegradability (K. et al. 2019). Bioplastics have been used for various industrial applications, for example, disposable housewares, medical devices, purchaser hardware, bags, and food packaging. When these materials are used for food contact, they must preserve the food quality and ensure that they do not impart any quality to food that could alter 
its sensory properties or present a risk to consumer health (Aznar et al. 2019).

This study is focused on the investigation of a biodegradable PVA-based material proposed for use in food packaging. PVA is among the synthetic polymers widely used for food packaging owing to its biodegradability, nontoxicity, good film-forming ability, water processability, ready availability, and low cost. This polymer has numerous applications, including as food packaging material (as film, layer in composite films, coating for films of different nature), as a coating agent for food supplements, protein purification, enzyme immobilization, membrane separation, pharmaceutical and cosmetics industrial use, and several medical applications, as well as in the paper and textile industries (Tripathi et al. 2009). It has been utilized in the commercial packaging industry because of its unique attributes including excellent film-forming ability, biodegradability, barrier to gases, and optical and mechanical properties (Mittal et al. 2016). However, PVA polymers still suffer from issues related to high water solubility, low tensile strength, and high degree of water absorption. The tendency for food to interact with its packaging is a factor that can significantly affect food quality, appearance, and shelf life. These issues can be overcome by the fabrication of polymer blends with cross-linking materials that improve the ideal properties of the film (Sachin Mane and Chavan 2016). Therefore, improving the stability of PVA films is essential for its application in different fields. As reported in the literature (Yao et al. 2003; Figueiredo et al. 2009), physical and chemical cross-linking are both effective routes, with chemical cross-linking most frequently employed. Cross-linking reagents are critical, and include organic and inorganic reagents. Organic components including dimethyl carbonate ( $\mathrm{Li}$ et al. 2017), formaldehyde (Pan et al. 2015), glutaraldehyde (Destaye et al. 2013), dicarboxylic acids (Siracusa et al. 2008), and so forth (Gohil et al. 2006; Tang et al. 2007); inorganic reagents including phosphoric acid (Prajapati et al. 2010) and boric acid (Chen et al. 2015), which are capable of reacting with the hydroxyl group of PVA, can be used to fine-tune its physicochemical properties.

Cross-linking of PVA with different organic acids is an extremely attractive approach, as the resulting PVA system may have unreacted functionality which gives explicit selectivity to the polymer matrix. In this respect, multicarboxylic acids are able to form multiple ester linkages to produce a stable three-dimensional PVA network (Pangon et al. 2016). Cross-linking thus introduces reactive carboxylic acid groups into the PVA matrix and increases the number of active sites on PVA, which enables ion transport via hydrogen bonding. The interaction of the hydrophilic groups with water molecules and the attraction of the hydrophobic groups to the surface of the material reduce the surface tension arising from the interaction of a solid material with a solution, thus increasing mechanical stability. Gohil et al. (2006) investigated the efficiency of oxalic acid as a cross-linker, and found that the wettability and phase morphology of PVA was enhanced. Birck et al. (2014) proposed the use of a PVA film cross-linked with citric acid and cyclodextrin as a dynamic food packaging material. It is well reported in the literature that PVA or PVA-polymer blends can be cross-linked using multi-carboxylic acids such as oxalic, citric, malic, succinic, and tartaric acid to achieve improved thermomechanical stability for use in packaging applications (Park et al. 2001; Gohil et al. 2006; Olivato et al. 2013; Suganthi et al. 2018). While numerous techniques have been proposed for crosslinked PVA networks, few works have undertaken a comparative evaluation of appropriate cross-linkers for PVA films used for food packaging. To this end, the objective of the present study is to investigate the physicochemical and biological properties of PVA film cross-linked using three different organic acids-malic acid, tartaric acid, and lactic acid-and to evaluate their bactericidal activity with respect to their potential as food packing materials. The results clearly show that the film microstructure plays a very important role (Alakanandana et al. 2016). It has been shown that an anti-adhesion strategy which prevents the initial bacterial adhesion on the film surface is most successful. Functional groups present in organic acids (OAs) can actively participate in hydrogen bonding, thus enhancing the thermomechanical stability and bactericidal activity of PVA film. The focus of this study is to demonstrate the effects of OAs on water absorption and thermal and mechanical properties. In addition, the study is aimed at determining the role of OAs with respect to the natural antibacterial properties of PVA film in order to gain a deeper understanding of the relationship between OAs and the morphological and biological properties of the PVA films.

Especially, the pathogenic bacterial contamination and creating destruction have serious dangerous for wide-coming to. Specifically, to worry in emergency clinic achieved disease, for example, entryway holders and latrine spots are the bowls of pathogenic microorganisms (Vignesh et al. 2019). Escherichia coli (E. coli) and Staphylococcus aureus (S. aureus) are among the most common species of gramnegative $\left(\mathrm{G}^{-}\right)$and gram-positive $\left(\mathrm{G}^{+}\right)$bacteria, respectively, which bring clinical segments. S. aureus is a humanoid presence yet, in addition, a shared grouping of grave disease, ranging from minor skin infections to progressively attentive of life-threatening wound and infections of the circulatory system. E. coli is one sort of significant reasons for contamination at copious spots in bodies of both animals and 
human beings. The custom of antibiotics is insecure for the dealing of bacterial illnesses with their infectious (Vignesh et al. 2018). Novel strategies are thus critical to perceive and advance the ensuing age of specialists or medications to control bacterial diseases though sanitation preparing, and instance of dousing the microscopic organisms over the genuine antibacterial reagents (Suganthi et al. 2018).

This study demonstrates that modification of PVA utilizing different OAs can significantly affect the hydrophilic/hydrophobic space microstructure, which results in bactericidal activity. Consequently, we aim to determine the effects of a cross-linking agent on the physicochemical properties, microstructure, and bioactivity of PVA films. Three cross-linking agents, i.e., lactic acid, tartaric acid, and malic acid, were used to evaluate the impact of these OAs on the mechanical and biological properties, water absorption, water solubility, optical properties, and bactericidal activity, with a view towards their use in food packaging applications.

\section{Materials and methods}

\section{Materials}

Commercial powder polyvinyl alcohol (PVA) (99.7\% hydrolyzed, MW 115,000) was obtained from Loba Chemie, India. Tartaric acid (TA), lactic acid (LA), and malic acid (MA) were obtained from SRL Chemicals. Sulfuric acid (98\%) was obtained from S.D. Fine Chemicals, India. Microbiological media were obtained from HiMedia Laboratories Pvt. Ltd. (Mumbai, India). All chemicals were used as received. Deionized (DI) water $(18.4 \mathrm{M} \Omega \mathrm{cm})$ obtained from Millipore was used during all experiments.

\section{Film preparation}

Films were obtained using a solution-casting technique (Pereira et al. 2015). First, $100 \mathrm{~mL}$ of $4 \mathrm{wt} \%$ PVA solution was prepared by dissolving a specified amount of PVA in deionized water at $85{ }^{\circ} \mathrm{C}$ followed by mechanical stirring until a clear solution was obtained. The PVA solution was cooled for $4 \mathrm{~h}$, after which $10 \mathrm{wt} \%$ of MA, TA, and LA in proportion to PVA was added as a cross-linker, followed by the dropwise addition of sulfuric acid to catalyze the reaction, which was maintained at room temperature. The mixture was stirred at room temperature for $1 \mathrm{~h}$ to complete the cross-linking reaction. The viscous solutions were cast onto Petri dishs to form a film by evaporating the solvent at room temperature. Pure PVA film was prepared for comparison. After evaporation of the solvent, the films were peeled from the Petri dishs.

\section{Characterization of PVA film properties}

\section{Physicochemical characterization}

Successfully synthesized PVA/OA solutions were characterized using a PerkinElmer Lambda 19 UV-Vis spectrophotometer. The FTIR spectra of the PVA/OA solutions were recorded using Fourier transform infrared spectroscopy (PerkinElmer Spectrum RX I) using in a range of $400-4000 \mathrm{~cm}^{-1}$. Powder X-ray diffraction (XRD) was carried out using the Rigaku Miniflex-II X-ray diffractometer (Japan) $[\lambda(\mathrm{Cu}-\mathrm{K} \alpha)=1.54 \AA]$. Thermogravimetric analysis of the PVA/OA solutions was carried out with a PerkinElmer Diamond TG/DTA thermogravimetric analyzer by heating the samples from 30 to $600{ }^{\circ} \mathrm{C}$ in increments of $10{ }^{\circ} \mathrm{C} \mathrm{min}{ }^{-1}$ under an argon atmosphere. The surface morphology of the pristine PVA and PVA/OA-crosslinked films was investigated by scanning electron microscopy (SEM; JEOL JSM-35CF), and gold film with thickness of $<100 \mathrm{~nm}$ was sputtered on the membrane surfaces using a JEOL JFC-1100 fine coat ion sputterer, prior to SEM study. The surface morphology of the films was studied by atomic force microscopy (AFM; Dualscope/Raster scope C26, DME, Denmark) to observe the three-dimensional (3D) image and to compute the roughness. Two measurable parameters identified with roughness were considered: Sa (normal of the total estimation of the height deviations from a mean surface), and $\mathrm{Sq}$ (root-mean-square normal of height deviations taken from the mean information plane). The average contact angle and surface wettability energy capacity of the composite films were investigated using a Phoenix-300 (Surface Electro-Optics) unit by a sessile drop method. Measurements were carried out in triplicate in different parts of the same membrane sample for accurate results.

\section{Antibacterial studies}

PVA and PVA/OA polymer solutions and fabricated polymer films were tested against $\mathrm{G}^{+}(S$. aureus $)$ and $\mathrm{G}^{-}(E$. coli) bacteria using a well diffusion method to determine their potential antibacterial activity (Suganthi et al. 2018). Mueller-Hinton agar was prepared and inoculated with the test bacteria. Next, the plate was arranged for agar wells by scooping out the media with a sterile plug borer $(8 \mathrm{~mm}$ in diameter). Each well was loaded with $100 \mu \mathrm{l}$ of PVA and PVA/OA polymeric solution and incubated at $37^{\circ} \mathrm{C}$ for $24 \mathrm{~h}$. After incubation, the inhibitory effect was estimated based on the clear zone in the solution. In the case that there was no clear zone around the well, it was assumed that the PVA and PVA/OA solution exerted no inhibitory effect on the bacteria. 


\section{Results and discussion}

Figure 1 shows the visual appearance of pristine PVA, PVA-TA, PVA-LA, and PVA-MA. The films have good transparency even at high carboxylic acid concentrations; thus, LA and MA have no effect on the transparency of the PVA.

\section{FTIR spectral analyses}

Figure 2 shows the FTIR spectral analysis of the pristine PVA and cross-linked PVA/MA, PVA/TA, and PVA/ LA. The characteristic broad band located at $3300 \mathrm{~cm}^{-1}$ appearing in the spectrum of the pristine PVA and crosslinked PVA is attributed to intermolecular and intramolecular hydrogen bonding and - $\mathrm{OH}$ stretching vibrations of PVA (Sedlařík et al. 2006). The peak around $2915 \mathrm{~cm}^{-1}$ is assigned to $\mathrm{C}-\mathrm{H}$ stretching, and the peak around $1430 \mathrm{~cm}^{-1}$ is assigned to out-of-plane $\mathrm{C}-\mathrm{H}$ vibrations. The results show that there is a new peak present at around $1718 \mathrm{~cm}^{-1}$ in the cross-linked PVA sample, which corresponds to the $\mathrm{C}=\mathrm{O}$ groups (Zhang et al. 2018). The large band at $1084 \mathrm{~cm}^{-1}$ is assigned to $\mathrm{C}-\mathrm{O}$ stretching vibrations that are present in all PVA/OA spectra (Mohsin et al. 2011). By contrasting the spectra of the crosslinked and pristine films, we can deduce that the preservation of all peaks shows that the molecular structure is maintained. The spectral analysis thus demonstrates both PVA and PVA/OA with few new peaks and different

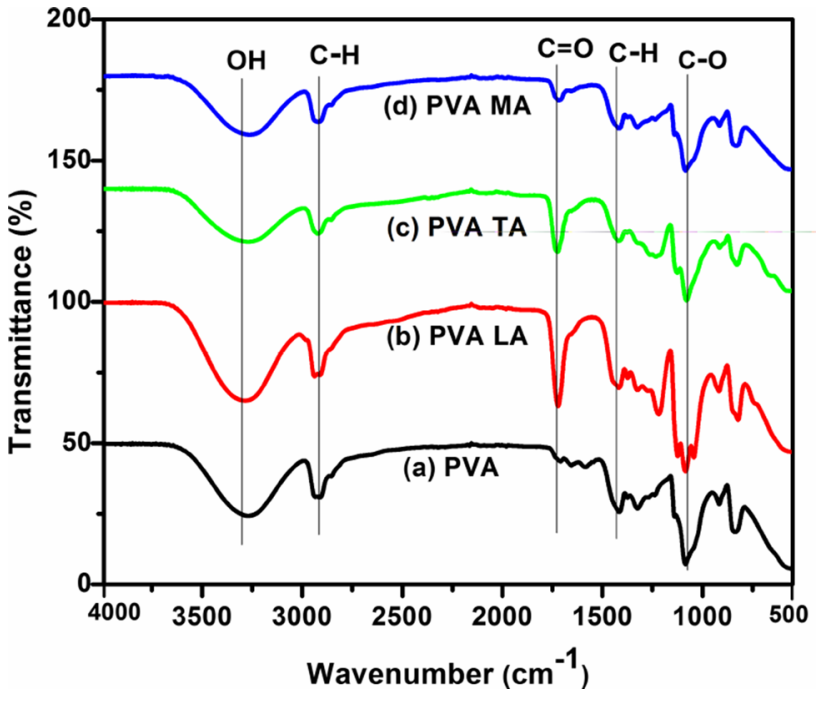

Fig. 2 FTIR spectra for pristine PVA and cross-linked PVA films

peaks appearing with a shift in their position, confirming effective cross-linking.

\section{Microstructural characterization of PVA/OA films}

\section{XRD studies}

The XRD patterns of pristine PVA, PVA/MA, PVA/TA, and PVA/LA films are shown in Fig. 3. The diffraction peak of
Fig. 1 The visual appearance of pristine PVA and cross-linked PVA films
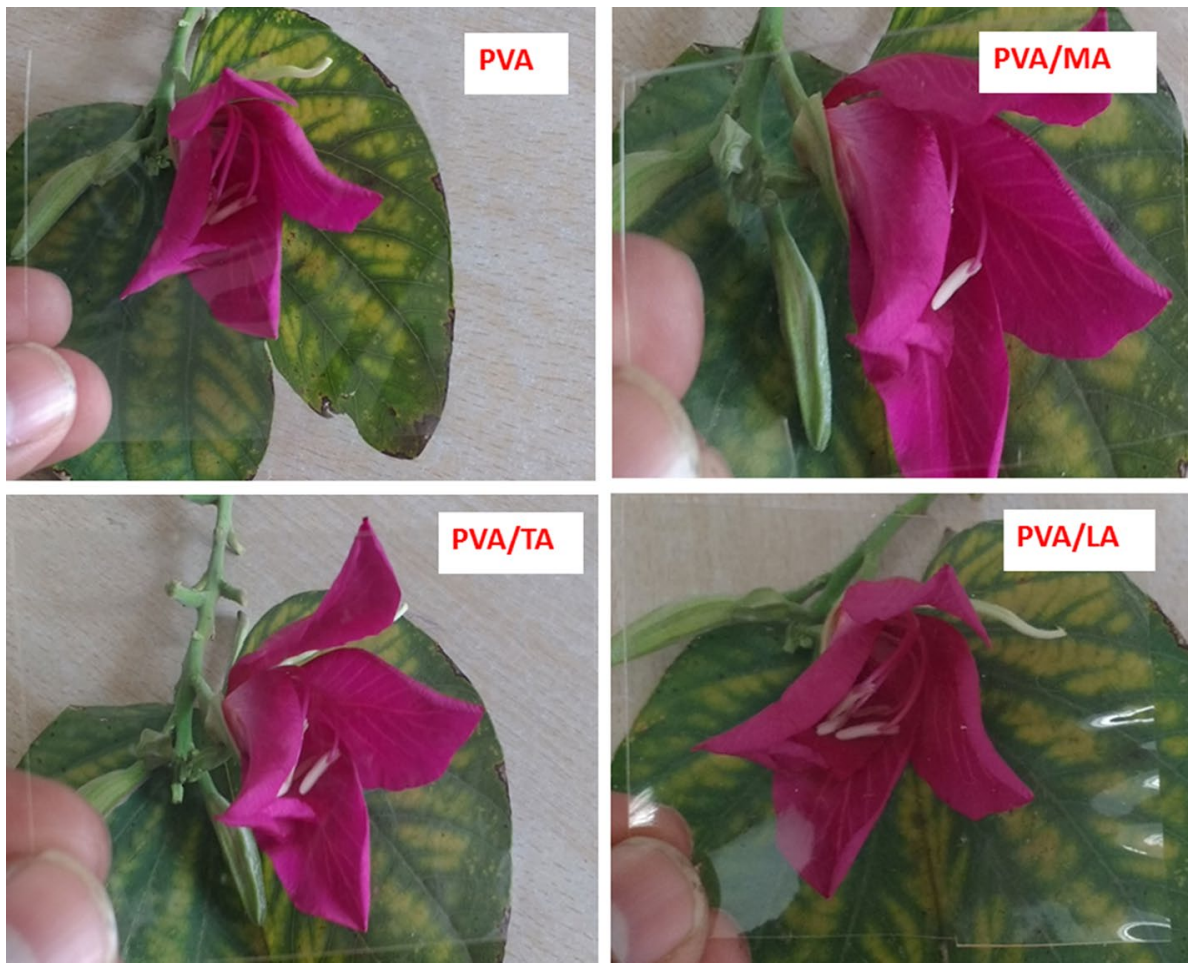


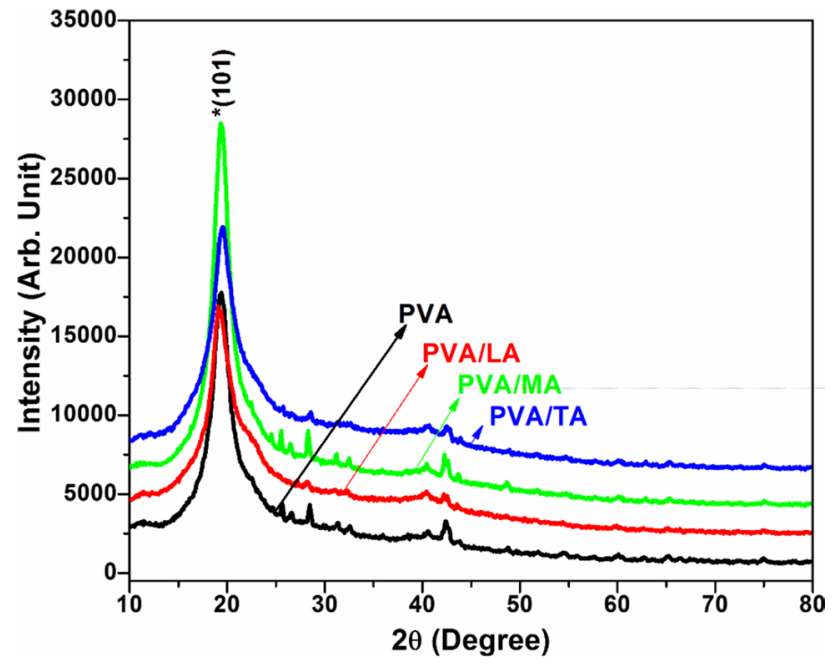

Fig. 3 X-ray diffraction patterns of PVA, PVA/LA, PVA/MA, and PVA/TA films

the PVA membrane at $2 \theta=19.4^{\circ}$ is due to the (101) crystal planes (Peres et al. 2016). The semicrystalline nature of the cast PVA films was improved by intermolecular $\mathrm{H}$-bonding, where a characteristic decline in peak intensity was observed. After cross-linking, this peak is broader and less intense, revealing the increased amorphous nature and decreased crystallinity of PVA. The presence of additional fine peaks in composite diffractograms was attributed to the formation of nanoscale solid acid phases. Cross-linking also led to multidirectional chain extension which resulted in the formation of the polymer network. The change in the amorphous nature of the film was affected by the cross-link thickness, where a change in semicrystalline nature was seen with the density of cross-linkages. Therefore, we can easily tune the mechanical properties of PVA biodegradable films by the number of cross-linkers.

\section{Surface morphology and topographical analysis by SEM and AFM}

The surface morphology of the fabricated films is shown in Fig. 4. As can be seen, while the SEM images of the surface of pristine PVA (Fig. 4a) appear homogeneous and smooth (Cano et al. 2015), the cross-linked PVA/MA (Fig. 4b) PVA/ TA (Fig. 4c), and PVA/LA (Fig. 4d) exhibit relatively rough surface morphology, possibly due to changes in microstructural characteristics introduced during the cross-linking reaction (Appu et al. 2013). Of note, SEM images of all films demonstrate no perceptible agglomeration, breaks, or pores, indicating that the cross-linker is well dispersed inside the PVA micro-domains with good compatibility between the components. Hence, all cross-linked PVA films exhibit a continuous matrix with good structural stability as demonstrated by SEM studies.

Surface topography based approaches for engineering antibacterial surfaces. In this area, the focus has been
Fig. 4 SEM images of a PVA, b PVA/MA, c PVA/TA, and d PVA/LA films
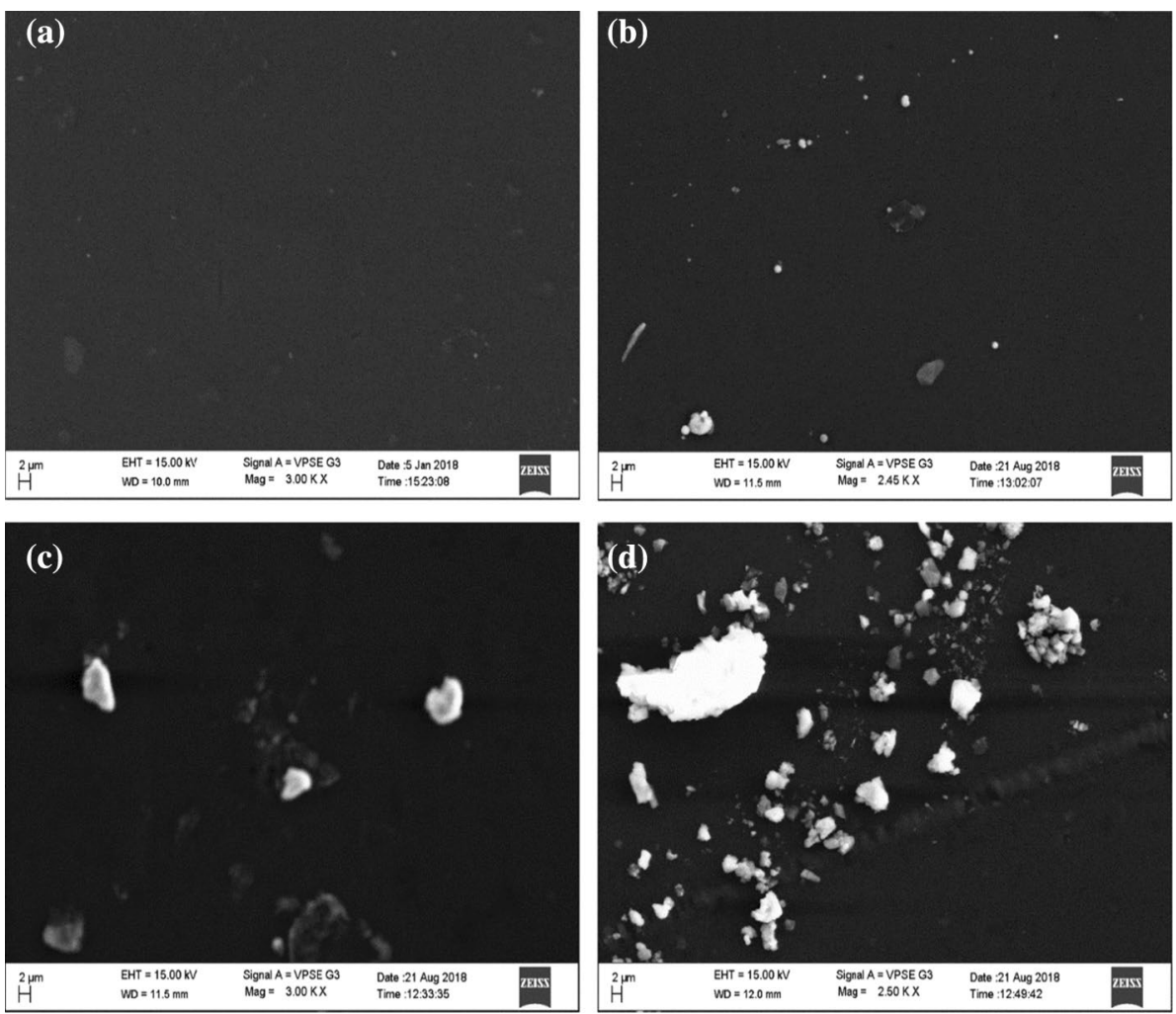
on the surface's intrinsic chemical behavior which retards the attachment and growth of bacterial cells. The primarily two types of antibacterial surfaces are (i) antibiofouling or bacteria-surfaces and (ii) bactericidal or bacteriasurfaces. Length-scale topographic features comparable to bacterial measurements, i.e. micro-to nano-meter scales, offer a promising new approach to cell-surface interaction regulation. It has been thought for decades that surface topography can only tolerate bacterial attachment and that many antibiofouling surfaces have been produced successfully (Hasan and Chatterjee 2015). AFM images of the pristine PVA and the cross-linked films are displayed in Fig. 5. As can be seen, for the pristine PVA, a smooth surface layer was obtained. The root-mean-square (RMS) roughness of the film was $10.05 \mathrm{~nm}$ (Fig. 5a). For the various cross-linked PVA films, the increased RMS roughness follows the order PVA/MA $<$ PVA/TA $<$ PVA/LA, as exhibited in Fig. 5b-d. The greatest roughness of $28.10 \mathrm{~nm}$ was obtained for the PVA/LA blend film/membrane. Figure 5 demonstrates the two-dimensional and three-dimensional surface morphology of the films. Most areas of the pristine PVA film are very smooth, with average root mean square roughness of $10.50 \pm 1.03 \mathrm{~nm}$ determined for a surface area of $2 \mathrm{~nm} \times 2 \mathrm{~nm}$ (Fig. 5a). By comparison, the RMS roughness estimates for the surface of films treated by cross-linking demonstrate a marked increase, with values of $14.84 \pm 1.50$, $16.76 \pm 1.73 \mathrm{~nm}$, and $28.66 \pm 2.37 \mathrm{~nm}$ for PVA/MA, PVA/ TA, and PVA/LA, respectively, as shown in Fig. 5b-d. The highest roughness was obtained for the PVA/LA blend film/ membrane.
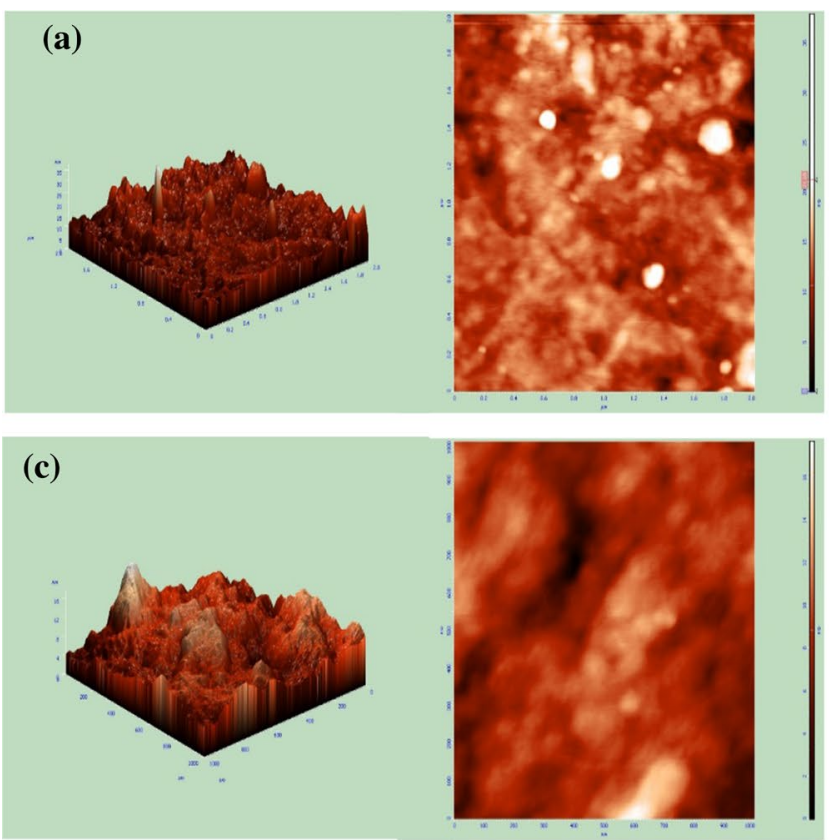

\section{UV spectral analyses}

Analysis of the UV spectra of pristine PVA, PVA/MA, PVA/ TA, and PVA/LA polymer solutions provides evidence of the successful blending of the polymer, and the results are shown in Fig. 6. It is clear that there is no absorption band in the visible region, but a peak is observed in the ultraviolet region of the electromagnetic spectrum for all the investigated samples, since the films are transparent (Sanuja et al.

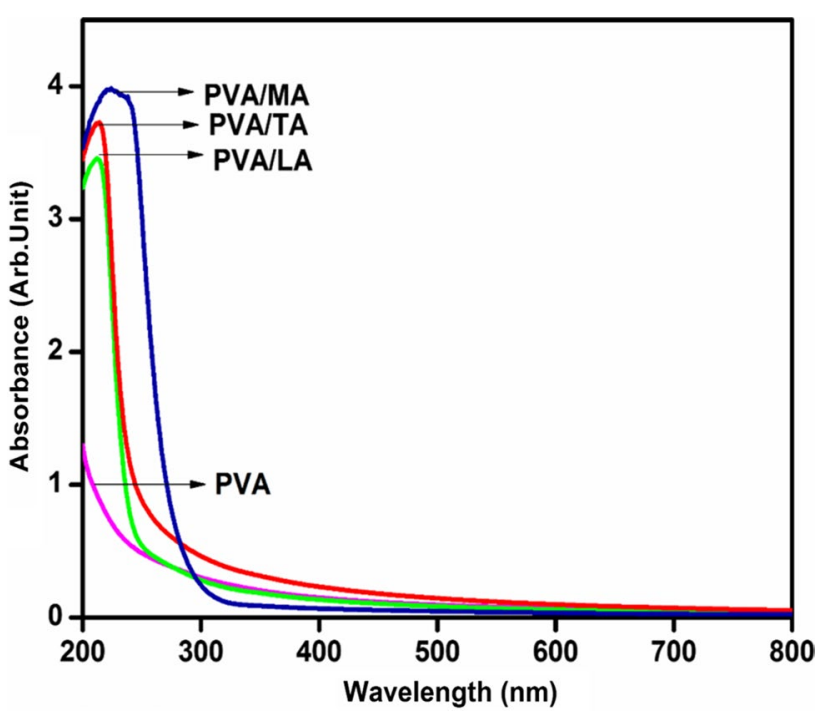

Fig. 6 UV-visible absorption spectra for pristine PVA and crosslinked PVA films
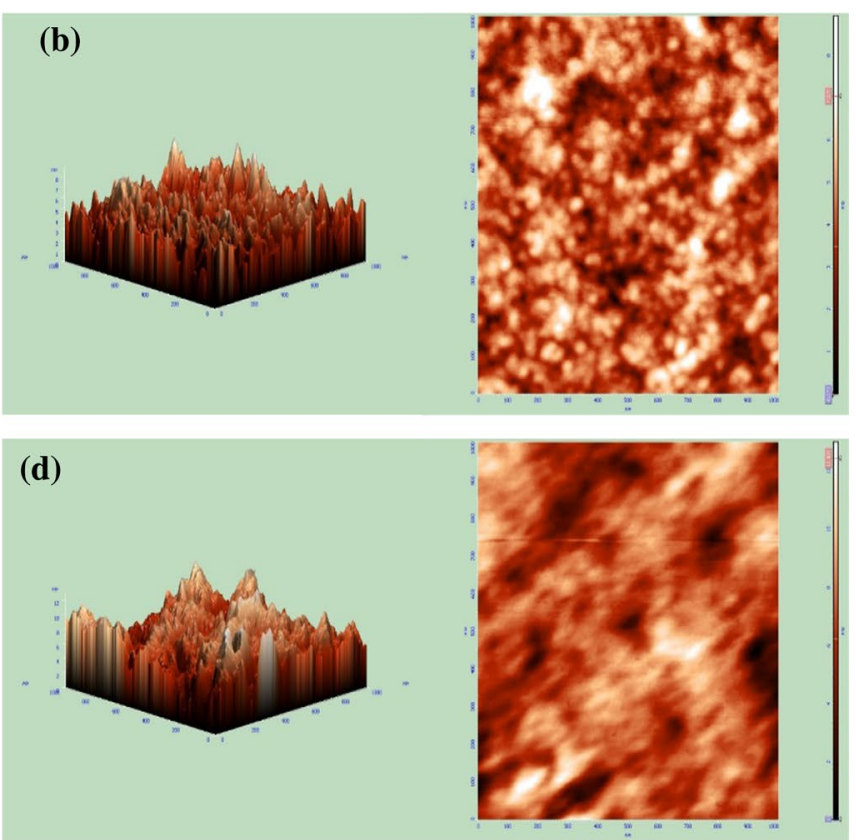

Fig. 5 AFM surface roughness images for the a PVA, b PVA/MA, c PVA/TA, and d PVA/LA films 
2015). The spectra of pure PVA show an absorption band at $217 \mathrm{~nm}$ which is due to $\mathrm{n} \rightarrow \pi$ transition, and another absorption shoulder-like band is observed at about 268-294 nm, due to $\pi \rightarrow \pi^{*}$ transition originating from unsaturated bonds of PVA. The maximum absorption is associated with the increase due to carboxylic acid, in comparison with the maximum absorption associated with PVA/MA, PVA/TA, and PVA/LA, appearing at $213 \mathrm{~nm}, 215 \mathrm{~nm}$, and $225 \mathrm{~nm}$, respectively. The shift of maximum absorption towards the lower-wavelength region indicates the presence of intermolecular hydrogen bonding between PVA and the different cross-linkers (Suganthi et al. 2016). Also, the degree of interaction seems to be higher for the PVA/LA system compared with PVA/MA and PVA/TA films.

\section{Thermal stability}

From the TGA thermogram in Fig. 7, it is clearly observed that the cross-linked PVA/MA, PVA/TA, and PVA/LA samples display three-stage degradation with better thermal stability compared with the pristine PVA, which exhibits only two-stage degradation. The minimum weight loss for all films occurs within a temperature range of $25-500{ }^{\circ} \mathrm{C}$, with the pristine PVA exhibiting the highest material loss ( $8.76 \%$ of original weight). This is due mainly to the loss of moisture adhesion and removal of water molecules from the polymer matrix, with the pristine PVA incurring the greatest loss of water molecules. The second stage of weight loss for the pristine PVA is then observed from 250 to $300{ }^{\circ} \mathrm{C}$, which is attributable to the breakage of $\mathrm{C}-\mathrm{C}$ and $\mathrm{C}-\mathrm{O}$ bonds, as the thermal energy is then able to degrade the linear chains of the pristine PVA (Gomaa et al. 2018). The ester linkages and additional hydrogen bonds present within the cross-linked

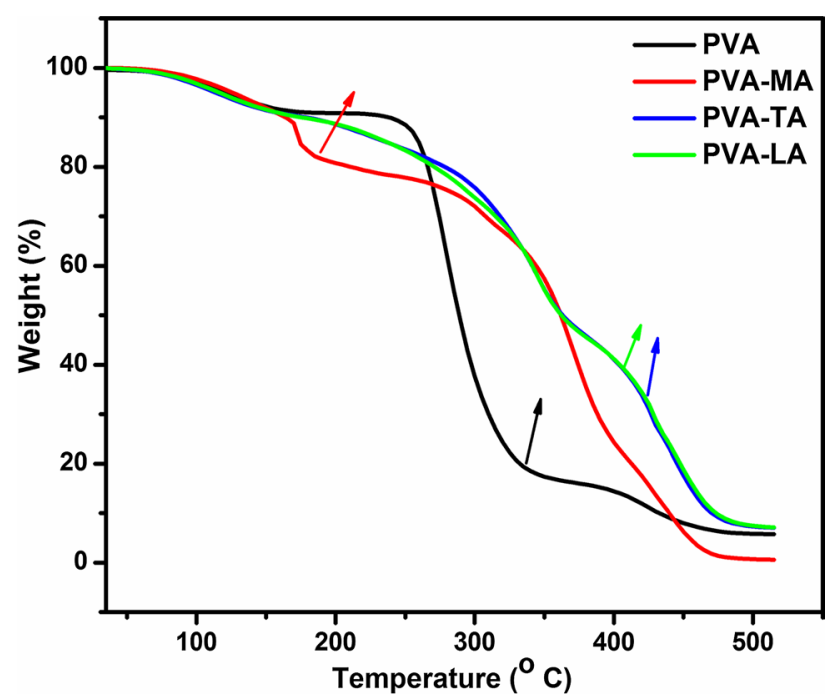

Fig. 7 TGA curves for a PVA, b PVA/MA, c PVA/TA, and d PVA/ LA films
PVA structures are gradually degraded in the range of $160{ }^{\circ} \mathrm{C}$. In this zone, all cross-linked PVA films are relatively stable, indicating that the thermal energy is not sufficient to break the ester linkages resulting from the reaction between the hydroxyl groups of the PVA and the carboxylic group of $\mathrm{OA}$, hindering facile degradation (Mohanapriya et al. 2016). Among the three cross-linked PVA networks, PVA/LA demonstrates the highest thermal stability because of the presence of functional groups that can actively participate in inter/intramolecular hydrogen bonding caused by the spatial proximity of the $-\mathrm{COOH}$ and $-\mathrm{OH}$ groups. The final level weight loss region above $350{ }^{\circ} \mathrm{C}$ represents the overall degradation of the PVA spine. As the thermal energy supplied starts to degrade $\mathrm{C}-\mathrm{C}$ and $\mathrm{C}-\mathrm{O}$ bonds, it is clear that the pristine PVA is unstable at this temperature. The three-dimensional network structure created as a result of intermolecular cross-linking of PVA chains via the crosslinker is the main reason for the higher thermal stability of the cross-linked PVA films. PVA/LA retains $83 \%$ of its original weight, versus $79 \%$ and $82 \%$ in the case of PVA/MA and PVA/TA, respectively, at $250{ }^{\circ} \mathrm{C}$. It can be concluded from the thermal degradation profiles that the PVA/LA film is the most thermally stable of the studied films.

\section{Contact angle measurements}

The contact angles of the pristine PVA and PVA/TA, PVA/ MA, and PVA/LA cross-linked samples were measured and are shown in Fig. 8. The water contact angle reflects the hydrophobicity/hydrophilicity of a surface (Thomas et al. 2009). Cross-linking by carboxylic acids removed

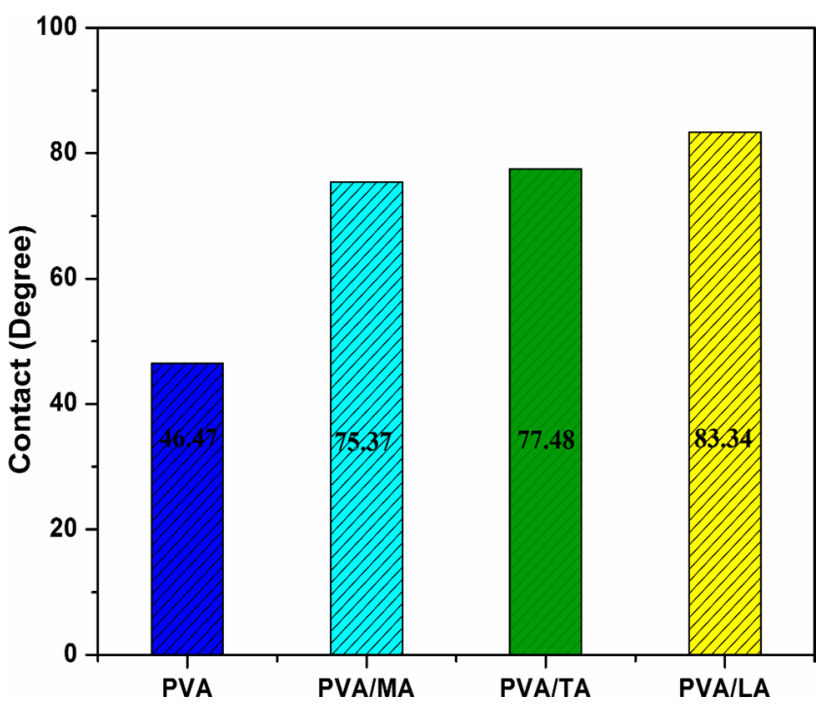

Fig. 8 Contact angles for a PVA, b PVA/MA, c PVA/TA, and d PVA/ LA films 
a large number of hydroxyl groups from the polymer chain. The maximum contact angles for PVA, PVA/MA, PVA/TA, and PVA/LA are $46.4^{\circ}, 75.3^{\circ}, 77.4^{\circ}$, and $83.3^{\circ}$, respectively. With the cross-linking of carboxylic acid, the film becomes moderately hydrophobic, as compared with the highly hydrophilic nature of PVA. These results demonstrate that PVA/LA has the greatest contact angle.

\section{Antimicrobial activity}

The antibacterial effects of pristine PVA and cross-linked PVA/OA membranes against two types of bacteria, $\mathrm{G}^{+}(S$. aureus) and $\mathrm{G}^{-}$(E. coli), were investigated utilizing the well diffusion technique, and the zone of inhibition for both bacterial species relative to the control are shown in Fig. 9. Antimicrobial activity, as determined by the diameter of the zone of inhibition, is dependent on the film characteristics, as shown in Table 1. Of note, the pristine PVA film showed no clear microbial inhibitory zone, whereas the OA crosslinked films showed specific microbial inhibitory zones against both bacteria using the well diffusion technique, demonstrating that fine-tuning of the polymer microstructure could have a significant affect on its antibacterial properties. Because there was no clear surrounding zone, we concluded that there was no zone of inhibition. In addition, the value of the diameter was zero. With regard to the surrounding clear zone, the PVA solution showed no inhibitory effects against either bacteria (Suma et al. 2017). The zone of inhibition for the samples demonstrated the following order: PVA $<$ PVA/ TA $<$ PVA/LA $<$ PVA/MA. Figure 10 presents a schematic comparison of the antibacterial activity of the pristine PVA film and PVA/OA cross-linked film. The antibacterial activity can be grouped into two types, characterized by bactericidal and anti-adhesion mechanisms. It is well-reported in the literature that there are four steps involved in bacterial proliferation, i.e., (1) adhesion of cells on a material surface,
Table 1 Antibacterial activity of prepared PVA and PVA/OA polymer solutions against different bacteria

\begin{tabular}{lcc}
\hline Sample name & \multicolumn{2}{c}{ Value of inhibition zone $(\mathrm{mm})$} \\
\cline { 2 - 3 } & E. coli & S. aureus \\
\hline PVA & $1.5 \pm 0.5$ & $1 \pm 0.5$ \\
PVA-TA & $6 \pm 1$ & $6.5 \pm 0.5$ \\
PVA-LA & $10 \pm 1$ & $9 \pm 1$ \\
PVA-MA & $9.5 \pm 0.5$ & $8.5 \pm 0.5$ \\
\hline
\end{tabular}

(2) accumulation of cells, (3) biofilm formation and development, and (4) proliferation of microbes for another cycle after liberation from the biofilm matrix; among these, the first step involving bacterial adhesion is the most significant (Arciola et al. 2015). Because reactive oxygen species (ROS) are involved in the probability, some active species are directly involved in the destruction of the outer area of the bacterial cell walls, causing serious damage to the microorganism. Likewise, the microorganism which is copious transports a negative charge despite the fact that the carboxylic groups will move a positive charge, and these roots electromagnetic attractive quality among the metals and fourth the microorganism that primes to oxidative kinetic and lastly microorganism (bacteria) will be dead. Cell grip to the embed surfaces is the basic beginning stage of the natural capacities at the interface affecting the cell reactions of the life form. Accordingly, cell attachment to the embed surfaces speaks to the underlying cooperation, and it is affected by the surface concoction and environmental qualities (Timofeeva and Kleshcheva 2011). The dissemination itself is reliant on the size, shape, and extremity of the dispersion material. The concoction structure and the cross-linking dimension of the films additionally influence this wonder (In et al. 2013). From the above talk, the main PVA/LA has affirmed to the higher antibacterial movement
Fig. 9 Antibacterial inhibitory effects of pristine PVA, PVA/ MA, PVA/TA, and PVA/LA polymer solutions
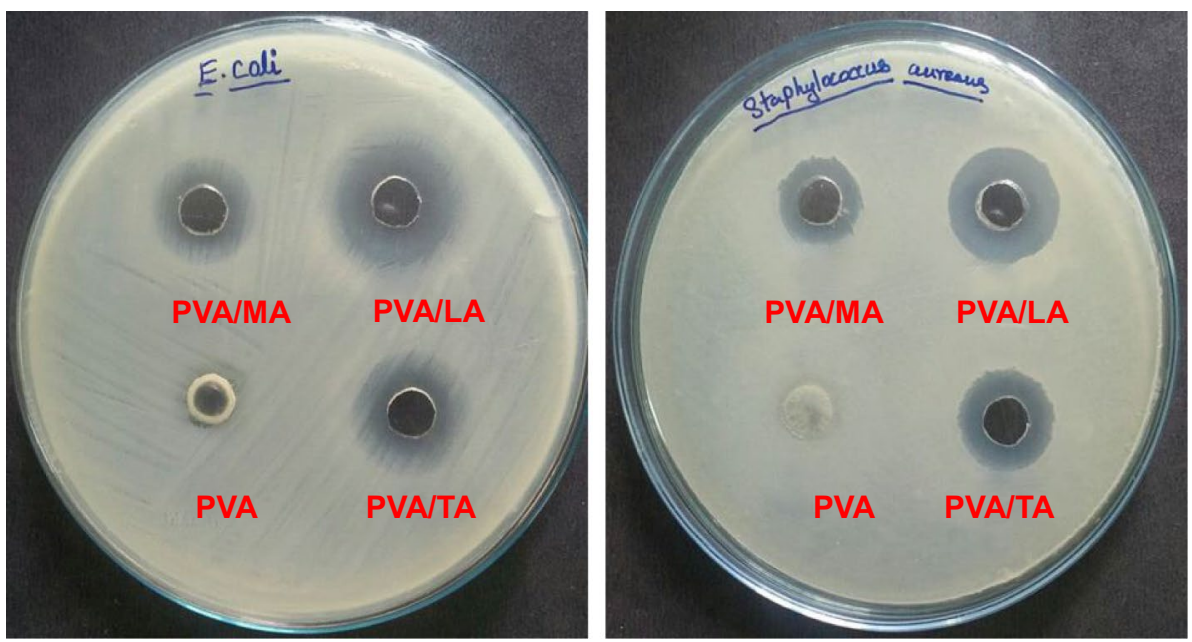
Fig. 10 Schematic representation comparing antibacterial activity of pristine PVA/ cross-linked film with different carboxylic acids

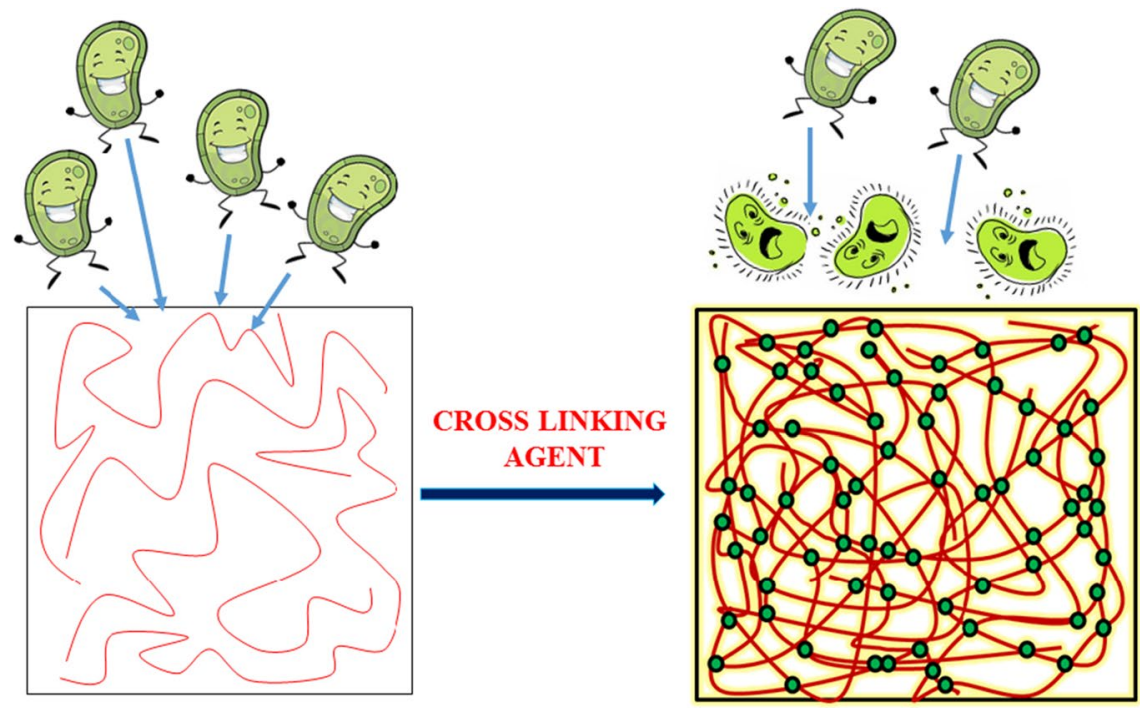

PVA FILM

PVA WITH CROSSLINKED FILM
PVA

has a place with the higher surface roughness (Tripathi et al. 2010; Park et al. 2011).

To this end, tuning of the material surface to prevent bacterial adhesion is more desirable than attempting to eliminate microorganisms after they are embedded in the PVA framework. Cross-linking with OAs tunes the microstructure of the PVA so that the surface is not favorable for bacterial adhesion. These outcomes propose that the antimicrobial exercises of natural acids can be impacted by the qualities of the earth, for example, $\mathrm{pH}$, grid structure and cell thickness. When all is said in done, the antimicrobial impact of natural acids is because of $\mathrm{pH}$ decrease in the earth. Be that as it may, numerous different factors, for example, chain length, level of stretching, and the proportion of undissociated types of natural acids influence the antimicrobial exercises of natural acids (Park et al. 2011). In addition, OAs including carboxylic corrosive utilitarian gathering is fit for moving through bacterial cell layers to reduce intercellular $\mathrm{pH}$.

The best inhibitory effects are found when LA is used as cross-linker, in contrast to the other two OAs used on this look at signifying that the occurrence of LA is valuable for antibacterial activity. The cause for the scrutiny is multi-faceted. (1) LA recreates the micro-area shape of PVA in a mode that PVA/LA keeps perfect surface features that repel bacteria while it originates into touch with the surface (2) LA itself acts as an antibacterial agent. LA alters local $\mathrm{pH}$ and/or consist of in chelation bond with metallic ion present within the bacterial portable divider that confines the absorption of vital increases and certainly causing the demise of germs. Indistinguishable, the antibacterial interest of given impetuses may be credited to the two viable mechanisms that mean, (1) the generation of upgrades phases of ROS, as an instance, relates of superoxide anion $\left(\mathrm{O}_{2}^{\bullet-}\right)$ radicals, hydroxyl radical $\left(\mathrm{OH}^{\bullet-}\right)$, and hydrogen peroxide $\left(\mathrm{H}_{2} \mathrm{O}_{2}\right)$, and (2) the deposition of carboxyl groups on the surface of the bacteria (Wu et al. 2018). Similar results are observed with LA-cross-linked films, which show good bacteriostatic properties against the pathogenic bacterial species $S$. aureus could be utilized in medical applications and protective packaging (Avrămescu et al. 2018). Based on the obtained results it is proposed that the nature of the surface together with surface topography play an important role in determining antibacterial activity. AFM and contact angle think about additionally are in great concurrence with these outcomes. Moreover, it has been discovered that the PVA-LA has higher zone restraint and also tends to be utilized to broaden nourishment time frame of realistic usability.

\section{Summary and conclusion}

In this study, three different organic acids were used for cross-linking with PVA, and their physicochemical and bactericidal properties were characterized. The functionality of the cross-linker significantly affected the physicochemical properties of PVA and improved bactericidal activity. Cross-linking with lactic acid led to substantially enhanced properties of the film by creating a good interaction between the hydrophobic and hydrophilic microstructure. LA acted as an antimicrobial agent, reducing the local $\mathrm{pH}$ of the bacteria, and the altered film permeability led to bacterial cell death, revealing the particular advantage of using LA as crosslinker. This is the first study to investigate the comparative

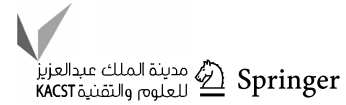


effects of cross-linking with malic acid, tartaric acid, and lactic acid on the antimicrobial properties of PVA, without the addition of antibiotics or inorganic materials, which has major implications for the use of PVA-based dynamic food packaging. The increased density from cross-linking, reducing the free volume of the surface, and the electrostatic and hydrophilic/hydrophobic bacteria-substrate interactions provide deeper insight into the bacterial adhesion process.

\section{Compliance with ethical standards}

Conflict of interest The authors declare that they have no conflict of interest with regard to the publication of this article.

Open Access This article is licensed under a Creative Commons Attribution 4.0 International License, which permits use, sharing, adaptation, distribution and reproduction in any medium or format, as long as you give appropriate credit to the original author(s) and the source, provide a link to the Creative Commons licence, and indicate if changes were made. The images or other third party material in this article are included in the article's Creative Commons licence, unless indicated otherwise in a credit line to the material. If material is not included in the article's Creative Commons licence and your intended use is not permitted by statutory regulation or exceeds the permitted use, you will need to obtain permission directly from the copyright holder. To view a copy of this licence, visit http://creativecommons.org/licenses/by/4.0/.

\section{References}

Agrillo B, Balestrieri M, Gogliettino M et al (2019) Functionalized polymeric materials with bio-derived antimicrobial peptides for "Active" packaging. Int J Mol Sci 20:601. https://doi.org/10.3390/ ijms20030601

Ahmed I, Lin H, Zou L et al (2017) A comprehensive review on the application of active packaging technologies to muscle foods. Food Control 82:163-178. https://doi.org/10.1016/j.foodc ont.2017.06.009

Alakanandana A, Subrahmanyam AR, Siva Kumar J (2016) Structural and electrical conductivity studies of pure PVA and PVA doped with succinic acid polymer electrolyte system. Mater Today Proc 3:3680-3688. https://doi.org/10.1016/j.matpr.2016.11.013

Appu SP, De SK, Khan MJ, Al-Harthi MA (2013) Natural weather ageing of starch/polyvinyl alcohol blend: effect of glycerol content. J Polym Eng 33:257-263. https://doi.org/10.1515/polye ng-2012-0048

Arciola CR, Campoccia D, Ravaioli S, Montanaro L (2015) Polysaccharide intercellular adhesin in biofilm: structural and regulatory aspects. Front Cell Infect Microbiol 5:1-10. https://doi. org/10.3389/fcimb.2015.00007

Avrămescu R-E, Ghica M, Dinu-Pîrvu C et al (2018) Superhydrophobic natural and artificial surfaces-a structural approach. Materials 11:866. https://doi.org/10.3390/ma11050866

Aznar M, Ubeda S, Dreolin N, Nerín C (2019) Determination of nonvolatile components of a biodegradable food packaging material based on polyester and polylactic acid (PLA) and its migration to food simulants. J Chromatogr A 1583:1-8. https://doi. org/10.1016/j.chroma.2018.10.055

Birck C, Degoutin S, Tabary N et al (2014) New crosslinked cast films based on poly(vinyl alcohol): preparation and physico-chemical properties. Express Polym Lett 8:941-952. https ://doi.org/10.3144/expresspolymlett.2014.95

Cano A, Fortunati E, Cháfer M et al (2015) Properties and ageing behaviour of pea starch films as affected by blend with poly(vinyl alcohol). Food Hydrocoll 48:84-93. https://doi.org/10.1016/j. foodhyd.2015.01.008

Chen J, Li Y, Zhang Y, Zhu Y (2015) Preparation and characterization of graphene oxide reinforced PVA film with boric acid as crosslinker. J Appl Polym Sci 132:42000. https://doi.org/10.1002/ app. 42000

Destaye AG, Lin C-K, Lee C-K (2013) Glutaraldehyde vapor crosslinked nanofibrous PVA Mat with in situ formed silver nanoparticles. ACS Appl Mater Interfaces 5:4745-4752. https://doi. org/10.1021/am401730x

Dhapte V, Gaikwad N, More PV et al (2015) Transparent ZnO/polycarbonate nanocomposite for food packaging application. Nanocomposites 1:106-112. https://doi.org/10.1179/2055033215Y.00000 00004

Figueiredo KCS, Alves TLM, Borges CP (2009) Poly(vinyl alcohol) films crosslinked by glutaraldehyde under mild conditions. J Appl Polym Sci 111:3074-3080. https://doi.org/10.1002/app.29263

Gohil JM, Bhattacharya A, Ray P (2006) Studies on the crosslinking of poly (vinyl alcohol). J Polym Res 13:161-169. https://doi. org/10.1007/s10965-005-9023-9

Gomaa MM, Hugenschmidt C, Dickmann M et al (2018) Crosslinked PVA/SSA proton exchange membranes: correlation between physiochemical properties and free volume determined by positron annihilation spectroscopy. Phys Chem Chem Phys 20:2828728299. https://doi.org/10.1039/C8CP05301D

Han J-W, Ruiz-Garcia L, Qian J-P, Yang X-T (2018) Food packaging: a comprehensive review and future trends. Compr Rev Food Sci Food Saf 17:860-877. https://doi.org/10.1111/1541-4337.12343

Hasan J, Chatterjee K (2015) Recent advances in engineering topography mediated antibacterial surfaces. Nanoscale 7:15568-15575. https://doi.org/10.1039/C5NR04156B

Huang T, Qian Y, Wei J, Zhou C (2019) Polymeric antimicrobial food packaging and its applications. Polymers 11:560. https://doi. org/10.3390/polym 11030560

In Y-W, Kim J-J, Kim H-J, Oh S-W (2013) Antimicrobial activities of acetic acid, citric acid and lactic acid against shigella species. $\mathrm{J}$ Food Saf 33:79-85. https://doi.org/10.1111/jfs.12025

Lei J, Yang L, Zhan Y et al (2014) Plasma treated polyethylene terephthalate/polypropylene films assembled with chitosan and various preservatives for antimicrobial food packaging. Colloids Surf B 114:60-66. https://doi.org/10.1016/j.colsurfb.2013.09.052

Li J, Li Y, Niu S et al (2017) Synthesis of a new "green" sponge via transesterification of dimethyl carbonate with polyvinyl alcohol and foaming approach. J Porous Mater 24:1595-1604. https://doi. org/10.1007/s10934-017-0399-9

Manikantan MR, Sharma R, Kasturi R, Varadharaju N (2014) Storage stability of banana chips in polypropylene based nanocomposite packaging films. J Food Sci Technol 51:2990-3001. https://doi. org/10.1007/s13197-012-0839-0

Mittal A, Garg S, Kohli D et al (2016) Effect of cross linking of PVA/ starch and reinforcement of modified barley husk on the properties of composite films. Carbohyd Polym 151:926-938. https://doi. org/10.1016/j.carbpol.2016.06.037

Mohanapriya S, Rambabu G, Suganthi S et al (2016) Bio-functionalized hybrid nanocomposite membranes for direct methanol fuel cells. RSC Adv 6:57709-57721. https://doi.org/10.1039/C6RA0 4098E

Mohsin M, Hossin A, Haik Y (2011) Thermal and mechanical properties of poly(vinyl alcohol) plasticized with glycerol. J Appl Polym Sci 122:3102-3109. https://doi.org/10.1002/app.34229

Okunola AA, Kehinde IO, Oluwaseun A, Olufiropo EA (2019) Public and environmental health effects of plastic wastes disposal: 
a review. J Toxicol Risk Assess 5:21. https://doi.org/10.23937 /2572-4061.1510021

Olivato JB, Nobrega MM, Müller CMO et al (2013) Mixture design applied for the study of the tartaric acid effect on starch/polyester films. Carbohyd Polym 92:1705-1710. https://doi.org/10.1016/j. carbpol.2012.11.024

Pan Y, Shi K, Liu Z et al (2015) Synthesis of a new kind of macroporous polyvinyl-alcohol formaldehyde based sponge and its water superabsorption performance. RSC Adv 5:78780-78789. https:// doi.org/10.1039/C5RA11958H

Pangon A, Saesoo S, Saengkrit N et al (2016) Multicarboxylic acids as environment-friendly solvents and in situ crosslinkers for chitosan/PVA nanofibers with tunable physicochemical properties and biocompatibility. Carbohyd Polym 138:156-165. https://doi. org/10.1016/j.carbpol.2015.11.039

Park SY, Jun ST, Marsh KS (2001) Physical properties of PVOH/chitosan-blended films cast from different solvents. Food Hydrocoll 15:499-502. https://doi.org/10.1016/S0268-005X(01)00055-8

Park SH, Choi MR, Park JW et al (2011) Use of organic acids to inactivate Escherichia coli O157: H7, salmonella typhimurium, and listeria monocytogenes on organic fresh apples and lettuce. J Food Sci 76:M293-M298. https://doi.org/10.111 1/j.1750-3841.2011.02205.x

Pereira VA, de Arruda INQ, Stefani R (2015) Active chitosan/PVA films with anthocyanins from Brassica oleraceae (Red Cabbage) as time-temperature indicators for application in intelligent food packaging. Food Hydrocoll 43:180-188. https://doi.org/10.1016/j. foodhyd.2014.05.014

Peres AM, Pires RR, Oréfice RL (2016) Evaluation of the effect of reprocessing on the structure and properties of low density polyethylene/thermoplastic starch blends. Carbohyd Polym 136:210 215. https://doi.org/10.1016/j.carbpol.2015.09.047

Prajapati GK, Roshan R, Gupta PN (2010) Effect of plasticizer on ionic transport and dielectric properties of PVA- $\mathrm{H}_{3} \mathrm{PO}_{4}$ proton conducting polymeric electrolytes. J Phys Chem Solids 71:1717-1723. https://doi.org/10.1016/j.jpcs.2010.08.023

Sachin Mane SP, Chavan N (2016) Effect of chemical crosslinking on properties of polymer microbeads: a review. Can Chem Trans 3:473-485. https://doi.org/10.13179/canchemtra ns.2015.03.04.0245

Sanuja S, Agalya A, Umapathy MJ (2015) Synthesis and characterization of zinc oxide-neem oil-chitosan bionanocomposite for food packaging application. Int J Biol Macromol 74:76-84. https://doi. org/10.1016/j.ijbiomac.2014.11.036

Sedlařík V, Saha N, Kuřitka I, Sáha P (2006) Preparation and characterization of poly (vinyl alcohol)/lactic acid compounded polymeric films. Int J Polym Anal Charact 11:253-270. https://doi. org/10.1080/10236660600750190

Shankar S, Rhim J-W (2018) Bionanocomposite films for food packaging applications. In: Reference module in food science. Elsevier, Amsterdam. https://doi.org/10.1016/B978-0-08-100596-5.21875 $-1$

Siracusa V, Rocculi P, Romani S, Rosa MD (2008) Biodegradable polymers for food packaging: a review. Trends Food Sci Technol 19:634-643. https://doi.org/10.1016/j.tifs.2008.07.003

Suganthi S, Mohanapriya S, Raj V (2016) Biocomposite protonexchange membrane electrolytes for direct methanol fuel cells. J Appl Polym Sci 133:43514. https://doi.org/10.1002/app.43514
Suganthi S, Mohanapriya S, Raj V et al (2018) Tunable physicochemical and bactericidal activity of multicarboxylic-acids-crosslinked polyvinyl alcohol membrane for food packaging applications. ChemistrySelect 3:11167-11176. https://doi.org/10.1002/ slct.201801851

Suma GR, Subramani NK, Sachhidananda S et al (2017) Optical and electrical evaluation of $\mathrm{Ag} 0.5 \mathrm{Cu} 0.75 \mathrm{O}$ introduced poly(vinyl alcohol) based E. coli sensors. J Mater Sci Mater Electron 28:1313913148. https://doi.org/10.1007/s10854-017-7148-3

Tang Y-F, Du Y-M, Hu X-W et al (2007) Rheological characterisation of a novel thermosensitive chitosan/poly(vinyl alcohol) blend hydrogel. Carbohyd Polym 67:491-499. https://doi.org/10.1016/j. carbpol.2006.06.015

Thomas LV, Arun U, Remya S, Nair PD (2009) A biodegradable and biocompatible PVA-citric acid polyester with potential applications as matrix for vascular tissue engineering. J Mater Sci Mater Med 20:259-269. https://doi.org/10.1007/s10856-008-3599-7

Timofeeva L, Kleshcheva N (2011) Antimicrobial polymers: mechanism of action, factors of activity, and applications. Appl Microbiol Biotechnol 89:475-492. https://doi.org/10.1007/s0025 3-010-2920-9

Tripathi S, Mehrotra GK, Dutta PK (2009) Physicochemical and bioactivity of cross-linked chitosan-PVA film for food packaging applications. Int J Biol Macromol 45:372-376. https://doi. org/10.1016/j.ijbiomac.2009.07.006

Tripathi S, Mehrotra GK, Dutta PK (2010) Preparation and physicochemical evaluation of chitosan/poly(vinyl alcohol)/pectin ternary film for food-packaging applications. Carbohyd Polym 79:711716. https://doi.org/10.1016/j.carbpol.2009.09.029

Vignesh S, Muppudathi AL, Sundar JK (2018) Multifunctional performance of $\mathrm{gC}_{3} \mathrm{~N}_{4}-\mathrm{BiFeO}_{3}-\mathrm{Cu}_{2} \mathrm{O}$ hybrid nanocomposites for magnetic separable photocatalytic and antibacterial activity. J Mater Sci Mater Electron 29:10784-10801. https://doi.org/10.1007/ s10854-018-9144-7

Vignesh S, Suganthi S, Kalyana Sundar J et al (2019) Highly efficient visible light photocatalytic and antibacterial performance of PVP capped Cd:Ag: ZnO photocatalyst nanocomposites. Appl Surf Sci 479:914-929. https://doi.org/10.1016/j.apsusc.2019.02.064

Wu S, Zhang B, Liu Y et al (2018) Influence of surface topography on bacterial adhesion: a review (review). Biointerphases 13:60801. https://doi.org/10.1116/1.5054057

Yao L, Haas TW, Guiseppi-Elie A et al (2003) Electrospinning and stabilization of fully hydrolyzed poly(vinyl alcohol) fibers. Chem Mater 15:1860-1864. https://doi.org/10.1021/cm0210795

Zhang Y, Yi Z, Wei L et al (2018) Modified iron phosphate/polyvinyl alcohol composite film for controlled-release fertilisers. RSC Adv 8:18146-18152. https://doi.org/10.1039/C8RA01843J

Publisher's Note Springer Nature remains neutral with regard to jurisdictional claims in published maps and institutional affiliations. 